\title{
A diferença e a diversidade na sala de aula: identidades religiosas em jogo
}

\section{The difference and the diversity in the classroom: religious identities at stake}

\author{
Jakeline Aparecida Semechechem*
}

\begin{abstract}
RESUMO: Este artigo tem como objetivo apresentar como a diferença e a diversidade em sala de aula são expressas por meio da linguagem, pelo modo como os participantes interagem com as identidades sociais. Nessa perspectiva, o texto apresenta como alunos de uma turma de Ensino Médio de escola pública interagem tendo em vista as categorias de pertencimento religioso. Os pressupostos teóricos empregados são da Análise de Categorias de Pertencimento e os dados de interação utilizados na análise são resultantes de gravações audiovisuais de uma pesquisa qualitativa-interpretativa de cunho etnográfico. A análise mostra que a religião é um marcador social na sala de aula, o pertencimento a determinadas categorias religiosas são assumidos enquanto outros são omitidos, o que tem relação com o contexto no qual a escola está inserida. Esses resultados apontam para a relevância do olhar para a diversidade e a diferença na sala de aula.
\end{abstract}

PALAVRAS-CHAVE: Diversidade. Identidades sociais. Sala de aula.

ABSTRACT: This article aims at presenting how the difference and the diversity in the classroom are expressed through language based on the way the participants interact with social identities. In this perspective, this text presents how High School students from a public school interact with categories of religious groups. The theoretical background that based the data analysis is the Membership Categorization Analysis and the data used in the analysis are the results of audiovisual recordings of a qualitative-interpretative ethnographic research method. The analysis shows that religion is a social marker in the classroom. Some religious identities were assumed, by the other side, some identity religious were rejected. These results point out the importance of looking at diversity and difference in the classroom.

KEYWORDS: Diversity. Social identities. Classroom.

\footnotetext{
* Doutorado em Letras na Universidade Estadual de Maringá (UEM/PR), com estágio de doutoramento na Universidade Coimbra (UC/PT). Mestrado em Letras na Universidade Estadual de Maringá. Graduação em Letras na Universidade Estadual do Centro-Oeste. E-mail: jakeline.semechechem@gmail.com.
} 


\section{Introdução}

Atualmente, as identidades sociais são vistas de uma forma fluída, sendo múltiplas, negociáveis, interacionalmente constituídas e linguisticamente exibidas (WOOLARD, 2007). Na pós-modernidade, as identidades não são consideradas como unificadas e estáveis, mas como fragmentadas, algumas contraditórias, outras, porém, não resolvidas, móveis e que se transformam, interpeladas pelas relações do mundo cultural (HALL, 2000). As identidades são, de acordo com Hall (2000, p. 108), "[...] multiplamente construídas ao longo de discursos, práticas e posições que podem se cruzar ou ser antagônicas".

$\mathrm{Na}$ sala de aula, os participantes podem tornar relevantes, assumir, negociar e/ou ratificar, além da identidade de professor e alunos, construções culturais e identitárias da comunidade, contribuindo para a manutenção do status quo (SEMECHECHEM; JUNG, 2008). Desse modo, necessitamos olhar no campo de estudos da linguagem para a sala de aula em termos de identidades sociais, pois elas nos possibilitam também ver como se constituem a diferença e a diversidade social nesse contexto, expressas primordialmente pelo uso da linguagem.

Neste artigo, mostramos como, na sala de aula de uma escola pública situada em um município na região sudeste do Paraná, os participantes, alunos e professores, lidam com a diferença por meio de sua(s) identidade(s) sociais religiosa(s). Para tanto, utilizando do recorte de uma pesquisa qualitativainterpretativa de cunho etnográfico, apresentamos a análise da identidade religiosa, na perspectiva teórica da Análise de Categorias de Pertencimento (SACKS, 1992; SCHEGLOFF, 2007a, 2007b), mostrando como a religião constitui um marcador social de diferença nesse contexto, lembrando que

marcadores sociais são características construídas socialmente de acordo com cada contexto sócio-histórico, estando atrelados aos sistemas de classificação social. Os marcadores estão associados à constituição de identidades sociais e, portanto, ao reconhecimento da alteridade, isto é, do que seja o outro (MONTAGNER et al, 2010, p. 16). 
$\mathrm{Na}$ primeira parte do artigo, apresentamos a abordagem teórica de identidades sociais na perspectiva da Análise de Categorias de Pertencimento. Na segunda parte, mostramos como uma turma de alunos do Ensino Médio lida com as identidades religiosas tornadas relevantes na interação durante as aulas e como essas identidades são assumidas, ou não, por eles. Por fim, apresentamos as considerações finais, destacando a importância do estudo de identidades no campo educacional.

\section{Identidades sociais: a análise de categorias de pertencimento}

Neste estudo, dentre as possíveis abordagens para identidades sociais, optamos pela Análise de Categorias de Pertencimento ${ }^{1}$ (MCA) (SACKS, 1992; SCHEGLOFF, 2007a, 2007b). No Brasil, essa abordagem tem crescentemente sido utilizada para tratar de identidades no campo da linguagem por vários autores, dentre eles, Abeledo (2008); Almeida (2009); Fortes (2010); Kniphoff (2012); Uflacker (2012); Abeledo et al (2014).

Os estudos sobre categorias de pertencimento começaram a ser desenvolvidos por Sacks, que introduziu o conceito de dispositivos de categorização para estudar como as pessoas organizam o mundo social em coleções de categorias. Posteriormente, essa abordagem foi rediscutida por Schegloff (2007a, 2007b), que introduziu alguns pressupostos sequenciais e analíticos da Análise da Conversa Etnometodológica, uma tradição de pesquisa de origem anglo-norte-americana, de base sociológica que busca o "[...] estudo da ação social humana situada no espaço e no decorrer do tempo real" (GARCEZ, 2008, p. 17). As ações são constituídas pelo uso da linguagem em interação social, são organizadas em sequências de elocuções produzidas por diferentes participantes (LODER; SALIMEN; MÜLLER, 2008). Nessa perspectiva, é relevante

\footnotetext{
${ }^{1}$ Membership Categorization Analysis.
} 
analisar as categorias de pertencimento levando em conta a sequência interacional, o que buscamos fazer neste artigo.

O dispositivo de categorização, proposto por Sacks, conforme ressalta Schegloff (2007a), trata-se de um conjunto de práticas usadas pelas pessoas para se referirem umas às outras: o trabalho de fazer descrições e a seleção de palavras. Um dispositivo de categorização é composto de duas partes: de uma ou mais coleção(ões) de categorias e de algumas regras de aplicação.

De acordo com Schegloff (2007a), elas podem ser descritas em palavras e podem ser homem, mulher, velho, criança, médico, professor, protestante, conservador etc. Essas categorias de pessoas, ou membros da sociedade, como define Sacks (1992, p. 467), que se configuram na interação na vida social, não são um simples agregado de categorias, mas são organizadas dentro de coleções que andam juntas, por exemplo, "[masculino / feminino]; [budista / católico / judeu / muçulmano / protestante...]), [calouros / juniores / seniores / estudantes de pós-graduação...]; [americano/ canadense / francês...] etc.". Ainda, certos tipos de coleções podem ter alternativas de categorias, por exemplo, para idade, são usados números cardinais, um ano de idade, 2 anos de idade ou 40 anos de idade etc., ou grupos como bebê, criança, velho etc. Nesse sentido, Silverman (1998) salienta que cada identidade é ouvida como uma categoria de alguma coleção de categorias.

Há, também, diferenças entre as coleções, algumas são o que Sacks definiu como pn adequates ${ }^{2}$ e outras não. Essa pn adequacy significa que as categorias, em uma dada coleção, podem categorizar qualquer pessoa da sociedade, como por exemplo, as relacionadas a sexo e idade. Já outras coleções têm categorias delimitadas para grupos específicos e não se aplicam a todas as pessoas, por exemplo, calouro, estudante de pós-graduação, jogador de futebol etc. (SCHEGLOFF, 2007a).

\footnotetext{
${ }^{2}$ Usaremos o termo em inglês por falta de termo traduzido para o português. Como se trata de um termo da teoria, optamos por não traduzir literalmente para o português.
} 
As categorias apresentam, segundo Schegloff (2007a), algumas características específicas: riqueza de inferências, proteção contra indução e atividades ligadas a categorias. A riqueza de inferência diz respeito ao conhecimento de senso comum das pessoas, o qual as pessoas têm armazenado. Conforme Uflacker (2012, p. 42), "com isso, o que é conhecido para uma categoria é presumivelmente atribuído a cada um de seus membros". A proteção contra indução refere-se ao fato de que o conhecimento de senso comum, organizado sobre as categorias, é protegido contra indução, ou seja, "se um membro ostensivo de uma categoria infringir o que é 'conhecido' sobre os membros da categoria, então as pessoas não vão rever esse conhecimento, mas ver a pessoa como 'uma exceção', 'diferente' [...]"3 (SCHEGLOFF, 2007a, p. 470). Já as atividades ligadas a categorias ocorrem porque tipos de atividades, ações ou formas de conduta, conforme o conhecimento de senso comum, são reconhecidas como características particulares de coleções de categorias.

A asserção de que alguma atividade está vinculada a alguma categoria não é uma asserção sobre essa atividade e categoria; é uma asserção sobre o conhecimento de senso comum - uma asserção de que o conhecimento de senso comum afirma tal ligação (SCHEGLOFF, 2007a, p. 476) $)^{4}$.

Assim, se a pessoa realiza uma ação, desenvolve uma atividade, pode tornar relevante uma categoria.

Além de o dispositivo de categorização ser composto por coleções de categorias, conforme citado anteriormente, ele é composto por regras de aplicação. As regras de aplicação, segundo Schegloff (2007a), foram chamadas por Sacks, de regra de economia e regra de consistência. A regra de economia se

\footnotetext{
${ }^{3}$ No original: If an ostensible member of a category appears to contravene what is 'known' about members of the category, then people do not revise that knowledge, but see the person as 'an exception', 'different,' [...].

${ }^{4}$ No original: The assertion that some activity is tied to some category is not an assertion about that activity and category; it is an assertion about common-sense knowledge - an assertion that common-sense knowledge asserts such a connection.
} 
refere ao fato de que um único termo de categoria é, inicialmente, suficiente para fazer referência às pessoas (SCHEGLOFF, 2007a), mas obviamente outras categorias podem vir a ser usadas. A regra de consistência sustenta que, se várias pessoas estão sendo categorizadas, e se a primeira a ser categorizada é referida por alguma categoria da coleção de algum dispositivo de categorização, então, uma categoria ou outras categorias da mesma coleção podem ser usadas para categorizar pessoas subsequentes.

Schegloff (2007a) salienta que as categorias que compõem as coleções de categorias, um componente importante dos dispositivos de pertencimento, não são meros rótulos taxonômicos. Por conta disso, é preciso considerar como alguns dispositivos de pertencimento são ativados, isto é, tornados relevantes e, consequentemente, as suas categorias. Ele enfatiza a questão de relevância, uma vez que vários dispositivos de pertencimento são disponíveis com uma multiplicidade de categorias, sendo necessário ver como categorias se tornam relevantemente foco de orientação para se tornar chave de investigação. Conforme Almeida (2009), uma identidade ou categoria tornada relevante é aquela que, quando projetada por um participante, se constitui índice de orientação para algum(ns) do(s) participante(s) da interação. Kniphoff (2012, p. 28) complementa que a orientação tem relação "[...] com as possibilidades de ação e as relevâncias condicionais que são cumpridas no curso da fala. E é, portanto, sequencialmente destacada. Quando se fica no nível da projeção não há orientação sequencial [...]". Assim, como ressalta Uflacker (2012), o desafio dos analistas é descrever os modos como os participantes exibem essas orientações uns para os outros na interação.

Nesta seção, apresentamos a abordagem de identidades sociais adotada neste artigo, identidades como categorias de pertencimento, discutidas pelo viés da Análise de Categorias de Pertencimento. Na próxima seção, mostramos como os alunos de uma turma do ensino médio, por meio da linguagem, lidam com suas 
categorias, identidades religiosas na interação, ora não assumindo-as, ora associando-se a elas.

\section{A diversidade e a diferença: identidades religiosas na sala de aula}

Nesta seção, apresentamos a análise sequencial do modo como os participantes, alunos e professores de uma turma do Ensino Médio de escola pública em um município no sudeste do Paraná, lidam com suas categorias religiosas na interação. Os dados utilizados para análise, as gravações audiovisuais das aulas da turma, fazem parte de uma pesquisa qualitativa-interpretativa de cunho etnográfico e foram analisados conforme procedimentos da microetnografia (ERICKSON, 1992; GARCEZ; BULLA; LODER, 2014). Para apresentação da análise neste artigo, selecionamos dois segmentos ${ }^{5}$ de aulas, uma de Língua Portuguesa e outra de uma aula de Sociologia. Esses segmentos estão transcritos de acordo com as convenções Jefferson de transcrição (Anexo 1) e são analisados sequencialmente.

Na sequência interacional que apresentamos a seguir, Dalva, a professora de Língua Portuguesa, estava trabalhando sobre intertextualidade com os alunos, enquanto Saulo instalava a televisão de multimídia. Ela citava exemplos de intertextos, primeiro das obras de Salvador Dali e psicanálise, até mencionar um texto trabalhado por ela em uma aula anterior, o texto De menor. Ao mencionar o texto De menor, ela questiona os alunos sobre qual o intertexto bíblico que o autor fez, ao não receber a resposta dos alunos, Dalva fornece a resposta e quer saber quem não era católico.

5 Neste artigo, com base em Garcez, Bulla e Loder (2014), o termo segmento é usado para nomear uma unidade analítica e o termo excerto para se referir aos trechos de transcrição. 


\section{Excerto 1 (Segmento 6 "Referência ao texto escrito" - Aula de Língua Portuguesa)}

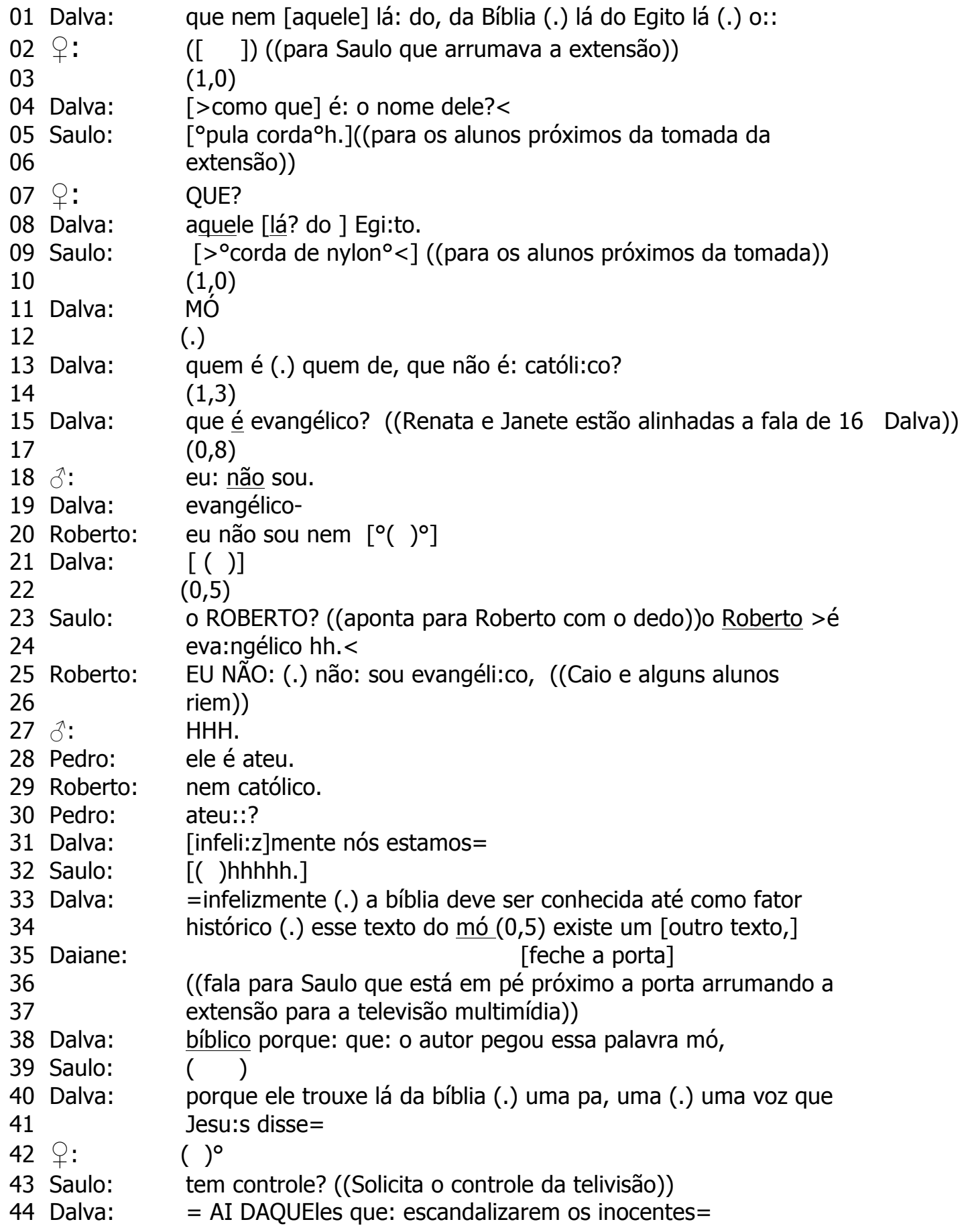


Na linha 01, Dalva faz uma iniciação que nem [aquele] lá: do, da Bíblia (.) lá do Egito lá (.) o::, a qual é marcada pelo prolongamento de vogal na final da elocução, entretanto, com essa iniciação, Dalva não pretende obter em adjacência uma reposta já conhecida por ela, uma vez que pelo auto reparo do, da Bíblia (linha 01) ela sinaliza não estar lembrando. Após um décimo de segundo (linha 03), ela faz outra iniciação [>como que] é: o nome dele?< (linha 04) sinalizada pela entonação ascendente. Na sequência, uma menina não identificada inicia um reparo QUE? (linha 07), acusando um problema de escuta, provavelmente, porque Saulo (linha 05) estava falando em sobreposição à fala de Dalva. Dalva leva a cabo o reparo e repete a iniciação aquele [lá? do ] Egi:to (linha 08) e, após um décimo de segundo (linha 10), ela fala a resposta MÓ (linha 11).

Entretanto, como os alunos não se autosselecionaram em adjacência para responder a questão do intertexto bíblico, Dalva faz outra iniciação e torna relevante as categorias de pertencimento religioso, católico e evangélico, perguntando quem é (.) quem de, que não é: católi:co?, (linha 13). Após um segundo e três décimos de segundo (linha 14), como não obtém resposta em adjacência, ela reformula a iniciação que é evangélico? (linha 15). Porém, ainda não obtém resposta em adjacência, o que é sinalizado pela pausa interturno de oito décimos de segundo (linha 17). Na sequência, alguns dos alunos se autosselecionam para rejeitar a categorização feita por Dalva que é evangélico? (linha 15): primeiro, um menino, que pode ser Estevan se autosseleciona eu: não sou. (linha 18), fornecendo a resposta à iniciação de Dalva (linha 15) e tornando relevante o seu não pertencimento à categoria citada por ela, uma vez que não era necessário ele se autosselecionar para dizer que não era evangélico, já que a iniciação era para saber quem era evangélico. Roberto (linha 20) se autosseleciona também para tornar relevante seu não pertencimento a esse grupo religioso, eu não sou nem $\left[{ }^{\circ}()^{\circ}\right]$, porém parte de sua elocução é incompreensível devido à fala sobreposta de Dalva (linha 21). 
Após cinco décimos de segundo (linha 22), Saulo se autosseleciona (linha 23) e com o volume de voz elevado diz: o ROBERTO? e aponta com o dedo para ele, categorizando-o como evangélico. Na sequência, Saulo reformula sua elocução para enfatizar a categorização de Roberto, o Roberto >é eva:ngélico hh.< (linhas 23 e 24), elocução seguida de riso. Roberto, em adjacência se autosseleciona e com o volume de voz elevado e prolongamento de vogal, rejeita a categorização feita por Saulo, EU NÃO: (.) não: sou evangéli:co, (linha 25). Nesse momento, alguns alunos que estavam alinhados ao trabalho de categorização de Roberto como evangélico por Saulo, começam a rir, conforme mostra a linha 27, um dos meninos ri com uma entonação acentuada, $\mathrm{HHH}$.

Pedro (linha 28) categoriza Roberto como ateu, ele é ateu.. Roberto (linha 29) afirma que também não é católico, nem católico., tornando relevante seu não pertencimento tanto ao grupo religioso evangélico como católico. Pedro (linha 30) com entonação ascendente e prolongamento de vogal sinalizando um questionamento diz: ateu::?., mas não é ratificado por Roberto, e ambos se alinham à fala de Dalva (linha 31). Saulo (linha 32) ainda continua engajado no trabalho de tornar relevante à categorização de Roberto como evangélico, o que se evidencia em sua elocução seguida de risos [( $) h h h h h$.$] . Contudo, os alunos se$ alinham à fala de Dalva, que dá continuidade ao cumprimento de seu propósito institucional, ou seja, trabalhar com os intertextos texto bíblico e o texto De menor (linha 38).

Nesse excerto, as categorias de pertencimento aos grupos religiosos são tornadas relevantes e os participantes se orientam para elas, sendo o pertencimento ao grupo evangélico rejeitado, embora Roberto (linha 29) também rejeite seu pertencimento ao grupo católico, sendo assim, categorizado como ateu (linha 28). No entanto, não é somente o trabalho de um dos meninos de tornar relevante seu não pertencimento ao grupo evangélico (linha 18) ou a categorização de Roberto como evangélico por Saulo (linhas 13, 15 e 19) seguida 
de risos dele e de outros alunos que apontam para a rejeição da associação a essa categoria, a essa identidade religiosa, mas principalmente o fato de Renata e Janete, que se declararam evangélicas no questionário aplicado à turma, não terem assumido o pertencimento a esse grupo religioso, mesmo estando alinhadas à iniciação de Dalva (linhas 13, 15 e 19), o que se evidenciou através de elementos multimodais (linha 13) na sequência interacional. Embora Dalva tenha feito três iniciações (linha 13, 15 e 19), Renata e Janete não se autosselecionam nem mesmo por meio de pistas extralinguísticas para revelar o seu pertencimento à categoria tornada relevante por Dalva.

A rejeição do pertencimento a essa categoria e o "mascaramento" dessa identidade religiosa evangélica ${ }^{6}$ pode ser compreendida por meio da sequencialidade da interação: primeiro, Dalva (linha 13) faz uma iniciação na qual pressupõe que a maioria pertence ao grupo católico quem é (.) quem de, que não é: católi:co?, com a pergunta já na negativa, ou seja, "quem seria o outro" que não faz parte desse grupo. Em seguida, ela faz outra iniciação categorizando que o não católico seria o evangélico que é evangélico? (linha 15), logo, pertencer ao grupo evangélico significa não pertencer ao grupo majoritário, ser "o outro no grupo". Isso é confirmado quando os demais participantes se engajam em um trabalho de rejeição (linhas 18, 20 e 25) da categoria tornada relevante por Dalva, quando Saulo por uma participação exuberante usa essa categoria para satirizar Roberto e é ratificado por risos de outros participantes.

Desse modo, essa sequência evidencia que pertencer ao grupo religioso evangélico é ser "o outro no grupo", é pertencer a uma minoria, rejeitada de antemão por alguns participantes que, mesmo não sendo membro dessa categoria, marcam o não pertencimento. Assim, o pertencimento ao grupo religioso evangélico, no caso a identidade evangélica além de tornar-se relevante

\footnotetext{
${ }^{6}$ Ressaltamos o caráter local e situado desse estudo. Não pressupomos de antemão que a identidade evangélica seja rejeitada, mas sim nessa sequência interacional.
} 
interfere na participação dos membros dessa categoria que optam por não relevar seu pertencimento e silenciam no evento.

Porém, o pertencimento a grupos religiosos, a identidade religiosa, nem sempre é rejeitada, ela é também ratificada e assumida, conforme mostra o excerto seguinte. Nesse evento da aula de Sociologia, Joana, a professora, solicitou que os alunos fizessem a cópia do assunto "Ciências Sociais" que ela ia escrever no quadro-negro.

Excerto 2 (Segmento 7 "Escrita: cópia do quadro" - Aula de Sociologia)

01 Joana: agora nós vamos estudar essa divisão das ciências sociais,

02 então escrevam lá (.) divisão,

03 Saulo: ah::

$04 \quad$ (.)

05 Joana: agora para a próxima aula por favor me tragam o livro, porque

06 senão eu vou ficar muito brava daí,

07 João: $\quad$ ô professora:: mas a revisão vai ser quando daí:,

08 Joana: vai ser quarta feira,

$09 \quad($.

10 Pedro: ${ }^{\circ}((\quad))^{\circ}$

11 Joana: sexta feira, é próxima aula tá,

12 Saulo: ah, sexta, sexta é é=

13 João: =sexta é recesso de segun[da e terça-feira]

14 Pedro: $\quad[>\text { segunda feira ninguém trabalhou }<]^{7}$

$15 \quad$ (.)

16 Saulo: é sexta-feira santa,

17 João: $\quad{ }^{\circ}(())^{\circ}$

18 Joana: a ${ }^{8}$, viu::, a já passou, já acabou a

19 João: $\quad\left[{ }^{\circ}\right.$ acabou ontem $\left.{ }^{\circ}\right]$

20 Pedro: $\quad\left[{ }^{\circ}((\quad))^{\circ}\right]$ ((fala para algum dos colegas próximos))

21 Joana: dia onze foi a

22 Marcos: vai ter domingo ainda?

23

((fazem a anotação no caderno))

7 Segunda-feira, após o domingo de Páscoa, é considerado Dia Santo no Calendário da Igreja Católica de rito ucraniano, embora oficialmente o município siga o calendário nacional. Nesse dia, a maioria dos estabelecimentos no município não atende, muitos porque seguem esse calendário e outros porque justificam não ter "movimento" no Município.

${ }^{8}$ Canções acompanhadas de coreografias, brincadeiras e danças. Na era pagã, comemorava-se a chegada da primavera, com a implantação do Cristianismo no ano de 988, também associaram à "Ressurreição de "Cristo: Usam-se dois nomes para esta tradição: " " e

${ }^{9}$ O segundo domingo após a Páscoa também é considerado Dia Santo de acordo com o Calendário da Igreja Católica de rito ucraniano ( falecidos durante a semana da Páscoa).

: Celebração pelos 
24 Pedro: $\quad$ cara esqueci pensei que era cinco horas ${ }^{\circ}$ (fala para Estevan)

25 Joana: abra a porta lá? > fazendo o favor<

Na sequência, Joana faz uma solicitação para que os demais participantes tragam o livro na aula seguinte (linha 05) e, posteriormente, relembra quando seria essa aula: sexta feira, é próxima aula tá, (linha 11) endereçando a sua fala a todos. Em adjacência, Saulo contesta ah, sexta, sexta é é= (linha 12) e tem sua elocução complementada por João que se autosseleciona e destaca que nesse dia seria recesso, =sexta é recesso de segun[da e terça-feira (linha13). Ambos se alinham com Joana e argumentam em relação a aula na sexta (linhas 16 e 17). Joana ratifica-os e destaca que as celebrações religiosas e os festejos em relação à Páscoa já haviam encerrado a , viu::, a : já passou, já acabou a . (linha 18). No entanto, ela faz uso de uma expressão " " usada pelo grupo católico de rito ucraniano para se referir às celebrações da Ressurreição de Jesus e é ratificada por João [ ${ }^{\circ} a c a b o u ~ o n t e m^{\circ}$ ] (linha 19) e por Marcos que se orienta para a questão e ressalta que os festejos e celebrações de Páscoa não encerraram vai ter domingo ainda (linha 22). Desse modo, ao tornarem explícito que compartilham do mesmo conhecimento em comum do que seria essa celebração e festejo em relação à Ressurreição de Jesus, citada por Joana (linha 18), João e Marcos assumem o pertencimento ao grupo étnico religioso católico-ucraniano. Nesse caso, a identidade religiosa é assumida.

O assunto feriado de Páscoa desencadeia ações de tornar relevante 0 pertencimento ao grupo religioso católico, logo da identidade católica, e de modo implícito de uma disputa para fazer-se membro competente dessa categoria, conforme mostra o excerto a seguir. 
Continuação do excerto 2 (Segmento 7 "Escrita: cópia do quadro" - Aula de Sociologia - 15/04/2009)

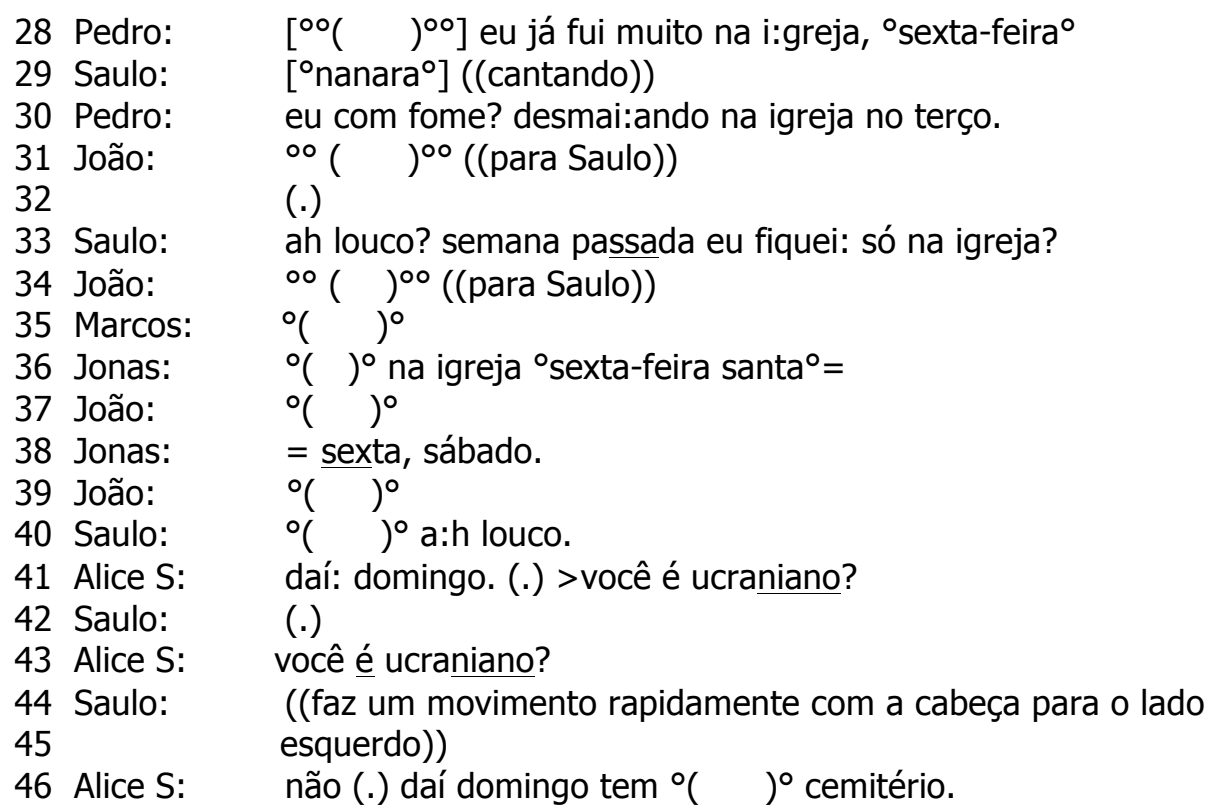

Enquanto copiavam o texto escrito no quadro-negro, alguns participantes se orientavam somente para a cópia do texto em seus cadernos, enquanto outros, além de realizarem a cópia do texto, mantinham concomitantemente conversas paralelas.

Pedro (linha 28), que mantinha um enquadre paralelo com Lúcia, Daiane e Silvane, o qual acontecia com entonação relativamente mais baixa [00( )oo] (linha 28), na sequencialidade de sua elocução com alteração na cadência rítmica, com intensidade maior eu já fui muito na i:greja, ${ }^{\circ}$ (sexta-feira) ${ }^{\circ}$ (linha 28), destaca que havia ido muito à igreja. Na linha 30 , em continuidade a sua elocução com entonação ascendente e também prolongamento de vogal, Pedro relata que quase desmaiou na igreja eu com fome? desmai:ando na igreja no terço., ele enfatiza as palavras "fome" e "desmaiando", o que pode ser compreendido que ocorreu por causa da prática de jejum, de acordo com a sequencialidade anterior pela 
referência da "sexta-feira"10 (linha 28). Desse modo, Pedro assume seu pertencimento ao grupo religioso católico e ainda mostra ser um membro competente que realiza as atividades ligadas a essa categoria de pertencimento religioso.

Saulo, que estava cantando $\left[{ }^{\circ}\right.$ nanara $\left.{ }^{\circ}\right]$ (linha 29) com intensidade baixa e em sobreposição ao turno relativamente mais baixo de Pedro [0\%( ) $\left.{ }^{00}\right]$ (linha 28), interrompe sua ação, o que torna explícito que ele se orientou para o turno de Pedro (linha 28) quando ele alterou a cadência rítmica ao falar da igreja. Na linha 33, após o turno de João (linha 31), Saulo se autosseleciona e com intensidade maior em relação à dos colegas, entonação ascendente e prolongamento de vogal diz: ah louco? semana passada eu fiquei: só na igreja?, tornando relevante, assim, seu pertencimento a esse grupo religioso e, ainda, como um membro assíduo. $\mathrm{Na}$ sequência, João, Marcos, Jonas e Alice S. se orientam para a questão e se engajam em uma conversa paralela a atividade de cópia.

João (linha 34), em adjacência ao turno de Saulo (linha 33), se autosseleciona, no entanto, seu turno é relativamente mais baixo, o que o torna inaudível. Marcos (linha 35) também toma o turno, demonstrando estar orientado para a categoria de pertencimento religioso tornada relevante. Em adjacência o turno de Jonas ${ }^{\circ}()^{\circ}$ na igreja ${ }^{\circ}$ sexta-feira santa ${ }^{\circ}=($ linha 36$)$, torna explícito que eles ainda estavam orientados para atividades ligadas a categorias de pertencimento religioso. Em contiguidade, João toma o turno novamente ${ }^{\circ}()^{\circ}$ (linha 37) e, em seguida, Jonas conclui sua elocução (linha 36) = sexta, sábado. (linha 38). Desse modo, ele também assume seu pertencimento ao grupo religioso por meio de uma atividade ligada a essa categoria, que era a participação na igreja católica na semana de Páscoa.

Assim, eles buscam, pela ação de tornarem explícita uma atividade ligada a categoria de pertencimento religioso, além de categorizarem-se como pertencentes

\footnotetext{
${ }^{10}$ Membros do grupo católico tem a prática jejuar na Sexta-Feira Santa ou ao menos abster-se de carne.
} 
a esse grupo, descrever-se também como membro competente que realiza todas as atividades ligadas a essa categoria: Pedro (linha 28 e 30) destaca uma atividade que ele realizara na sexta-feira, Saulo (linha 33) menciona que ficou a semana toda na igreja; Jonas cita a sexta-feira e o sábado (linhas 36 e 38), João, embora com turnos inaudíveis, também demonstra orientar-se para a questão (linhas 31 e 34), assim como Marcos (linhas 31, 34, 37 e 39). A identidade religiosa católica é assumida e negociada, um tenta descrever para o outro atividades ligadas a essa categoria para ser reconhecido como membro e membro competente. Além disso, há uma relação entre a identidade religiosa e a ucraniana, conforme mostra a continuação do excerto 15, quando Alice pergunta para Saulo de sua origem étnica daí: domingo. (.) > você é ucraniano? (linha 41), e, como não obtém a resposta em adjacência, ela faz novamente a iniciação você é ucraniano? (linha 43).

Dessa maneira, nesta seção, apresentamos como o pertencimento a grupos religiosos, a identidade religiosa também é tornada relevante, negociada, rejeitada e, por vezes, assumida nas aulas de uma turma do Ensino Médio. Dalva, a partir de sua iniciação, torna explícita a relevância de pertencimentos a grupos religiosos em uma oposição dicotômica, católico-evangélico. Em uma iniciação para saber quem não pertencia ao grupo católico, ela faz a categorização de quem seriam os evangélicos. Alguns participantes não pertencentes ao grupo evangélico se engajam no trabalho de tornar explícito seu não pertencimento a esse grupo. Saulo categoriza Roberto como evangélico para satirizá-lo, o que é evidenciado por seus risos e por risos de alguns participantes que também se engajam na ação. Renata e Janete, embora orientadas para a iniciação de Dalva, não assumem seu pertencimento ao grupo evangélico, desse modo, não assumem a identidade religiosa evangélica e, consequentemente, não participam do evento em relação à iniciação feita por Dalva.

No entanto, o pertencimento a grupos religiosos nem sempre é rejeitado, a identidade religiosa católica-ucraniana é assumida. $O$ que foi mostrado em outro 
evento das aulas da $3^{a}$ série do Ensino Médio quando, no alinhamento para a realização de uma atividade escrita, alguns participantes tornam relevante o feriado de Páscoa e se engajam na ação de tornar explícito que são membros do grupo religioso católico, logo, assumem suas identidades católica e católicaucraniana.

\section{Considerações finais}

A análise mostra que a religião é marcador social de diferença nessa escola e, por sua vez, na comunidade, a identidade religiosa não foi assumida quando foi relacionada ao grupo religioso evangélico. Ao tornar-se relevante na interação por um trabalho de categorização de "quem era evangélico" e ainda em uma oposição dicotômica com "quem não era católico era evangélico", as participantes evangélicas não revelam seu pertencimento a esse grupo religioso, mesmo diante da indagação da professora sobre quem era evangélico. Ainda no decorrer da interação, outros participantes se engajam num trabalho de rejeitar essa categoria desse pertencimento religioso, a qual é usada também por um dos participantes para satirizar o outro, num trabalho de categorização, seguido de risos e da orientação dos demais participantes, o que contribui também para que os membros dessa categoria de pertencimento ao grupo evangélico não assumam seu pertencimento no decorrer do evento. No entanto, nem sempre a identidade religiosa é rejeitada, a identidade católica é assumida quando tornada relevante. Os participantes assumem o pertencimento ao grupo religioso católico e católicoucraniano quando tornam explícito o entendimento em comum de uma atividade ligada àquela categoria, ainda em um trabalho de fazer-se membro por meio de descrições de ações ligadas à categoria de pertencimento religioso.

A não identificação das participantes com a identidade evangélica está associada ao pertencimento a um grupo minoritário e minoritarizado. A religião 
católica constitui-se a religião da maioria da população no município, há membros da Igreja Católica do rito latino e da Igreja Católica do rito ucraniano, além disso, a religião católica é um valor hegemônico, principalmente, por sua relação histórica com o letramento e por constituir-se como um dos valores sociais locais (SEMECHECHEM, 2010), o que também é evidenciado localmente na fala-eminteração, quando essa identidade religiosa é assumida. Assim, ser católico é interagir com valores locais. Cabe ressaltar que a questão em jogo não é o pertencimento a uma ou outra religião, ser católico ou evangélico, mas o pertencimento a grupos religiosos majoritários ou minoritários nesse contexto. Pois, em outra realidade social, na qual a religião evangélica fosse predominante e a religião católica fosse seguida por um grupo minitoritário, os resultados poderiam ser outros, a identidade evangélica poderia ser assumida e valorizada, pois bem como ressalta Hall (2000, p. 13), a identidade é uma "[...] 'celebração móvel': formada e transformada continuamente em relação às formas pelas quais somos representados ou interpelados nos sistemas culturais que nos rodeiam".

Em suma, o estudo da diferença e da diversidade social na escola por meio de identidades e de pertencimento a grupos sociais pode contribuir para que professores, pedagogos e demais profissionais da área educacional tenham uma metaconsciência (JUNG, 2009) da realidade local e desenvolvam ações que envolvam "pensar" como agir de modo que todas as identidades sejam assumidas e legitimadas.

\section{Referências}

ABELEDO, Maria Lopez O. Uma compreensão etnometodológica da aprendizagem de língua estrangeira na fala-em-interação de sala de aula. 2008. 217 f. Tese (Doutorado em Letras) - Instituto de Letras, Universidade Federal do Rio Grande do Sul, Porto Alegre, 2008. 
ABELEDO, Maria Lopez O. L et al. Uma compreensão etnometodológica de aprendizagem e proficiência em língua adicional. Trabalhos em Linguística Aplicada, Campinas, v.53, n.1, p. 131-144, 2014.

ALMEIDA, Alexandre do Nascimento. A construção de masculinidades na fala-eminteração em cenários escolares. 2009. Tese (Doutorado em Letras) - Instituto de Letras, Universidade Federal do Rio Grande do Sul, Porto Alegre, 2009.

ERICKSON, Frederick. Ethnographic microanalysis of interaction. In: LECOMPTE, M. D.; MILLROY, W. L.; PREISSLE, J. (Ed.). The handbook of qualitative research in education. Nova Iorque: Academic Press, 1992. p. 201-225.

FORTES, Mellisa Santos. Uma compreensão etnometodológica do trabalho de fazer membro na fala-em-interação de entrevista de proficiência oral em português como língua adicional. Tese (Doutorado em Linguística Aplicada) - Universidade Federal do Rio Grande do Sul, Porto Alegre, 2010.

GARCEZ, Pedro M. A perspectiva da Análise da Conversa Etnometodológica sobre o uso da linguagem em interação social. In: LODER, L. L; JUNG, N. M. Fala-eminteração social: introdução à análise da conversa etnometodológica. Campinas: Mercado de Letras, 2008a. p. 17-38.

GARCEZ, Pedro M.; BULLA, Gabriela da Silva; LODER, Leticia L. Práticas de pesquisa microetnográfica: geração, segmentação e transcrição de dados audiovisuais como procedimentos analíticos plenos. DELTA, 2014, vol.30, n.2, p. 257-288. Disponível em: <http://www.scielo.br/pdf/delta/v30n2/0102-4450-delta30-02-0257.pdf>. Acesso em: 15 fev. 2015.

GARFINKEL, Harold. Estudios em Etnometodología. Tradução de Hugo Antonio Pérez Hernáiz. Barcelona: Anthropos Editorial, 2006.

HALL, Stuart. A identidade cultural na pós-modernidade. Rio de Janeiro: DP \& A Editora, 2000.

JUNG, Neiva Maria. $A$ (re)produção de identidades sociais na comunidade e na escola. Ponta Grossa: Editora UEPG, 2009.

KNIPHOFF, Ana Maria. O gerenciamento de categorias de pertencimento no trabalho de avaliação pedagógica na fala-em-interação de sala de aula de EJA. 2012. 143 f. Dissertação (Mestrado em Letras) - Instituto de Letras, Universidade Federal do Rio Grande do Sul, 2012. 
LODER, Leticia L. O modelo Jefferson de transcrição: convenções e debates. In: LODER, Leticia L.; JUNG, Neiva M. (Org.). Fala-em-interação social: introdução à análise da conversa etnometodológica. Campinas: Mercado de Letras, 2008. p. 127-163.

LODER, Leticia L.; SALIMEN, Paola Guimaraens; MÜLLER, Marden. Noções fundamentais: seqüencialidade, adjacência e preferência. In: LODER, L. L; JUNG, N. M. Fala em interação social: Introdução à Análise da Conversa Etnometodológica. Campinas: Mercado de Letras, 2008. p. 39-58.

MONTAGNER, Paula et al. Diversidade e capacitação em escolas de governo: mesa-redonda de pesquisa-ação. Brasília: ENAP, 2010.

SACKS, Harvey. Lecture 6 - The MIR Membership Categorization Device. In: . Lectures on conversation. Oxford: Basil Blackwell, 1992. v.1-2.

SCHEGLOFF, Emanuel. A. A tutorial on membership categorization. Journal of Pragmatics, Amsterdam, v, 39, p. 462-482, 2007 a.

SCHEGLOFF, Emanuel A. Categories in action: person-reference and membership categorization. Discourse Studies, Abingdon, v. 9, p. 433-461, 2007b.

SEMECHECHEM, Jakeline Aparecida. Letramento e identidades sociais em um município multilíngue no Paraná. Dissertação (Mestrado em Letras) - Universidade Estadual de Maringá, Maringá, 2010.

SEMECHECHEM, Jakeline Aparecida; JUNG, Neiva Maria. A co-construção de identidades sociais em sala de aula. Uniletras, Ponta Grossa, v. 30, n. 1, p. 9-31, jan./jun. 2008.

SILVERMAN, David. Harvey Sacks: Social Science and Conversation Analysis. New York: Oxford University Press, 1998.

UFLACKER, Cristina Marques. Fazer avaliar na construção do participante competente em sala de aula. 2012. Tese (Doutorado em Linguística Aplicada) Universidade Federal do Rio Grande do Sul, Porto Alegre, 2012.

WOOLARD, Kathryn A. Bystanders and the linguistic construction of identity in face-to-back Communication. In: AUER, Peter. (Ed.). Style and Social Identities: alternative Approaches to Linguistic Heterogeneity. Berlim, New York: Mouton de Gruyter, 2007. p. 187-205. 


\section{Anexo 1}

\begin{tabular}{|c|c|c|}
\hline \multicolumn{3}{|c|}{ CONVENÇÕES DE TRANSCRIÇÃO } \\
\hline. & (ponto final) & entonação descendente \\
\hline$?$ & (ponto de interrogação) & entonação ascendente \\
\hline 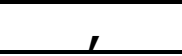 & (vírgula) & entonação intermediária \\
\hline : & (dois-pontos) & prolongamento do som \\
\hline- & (flecha para cima) & som mais agudo do que os do entorno \\
\hline- & (flecha para baixo) & som mais grave do que os do entorno \\
\hline- & (hífen) & corte abrupto na produção vocal \\
\hline fala & (sublinha) & ênfase em som \\
\hline FAla & (maiúscula) & $\begin{array}{l}\text { som em volume mais alto do que os do } \\
\text { entorno }\end{array}$ \\
\hline${ }^{\circ}$ fala $^{\circ}$ & (sinais de graus) & $\begin{array}{l}\text { som em volume mais baixo do que os do } \\
\text { entorno }\end{array}$ \\
\hline$>$ fala $<$ & $\begin{array}{l}\text { (sinais de maior do que e } \\
\text { menor do que) }\end{array}$ & fala acelerada \\
\hline$<$ fala $>$ & $\begin{array}{l}\text { (sinais de menor do que e } \\
\text { maior do que) }\end{array}$ & fala desacelerada \\
\hline$(2,4)$ & (números entre parênteses) & $\begin{array}{l}\text { medida de silêncio (em segundos e } \\
\text { décimos de segundos) }\end{array}$ \\
\hline (.) & (ponto entre parênteses) & $\begin{array}{l}\text { silêncio de menos de } 2 \text { décimos de } \\
\text { segundo }\end{array}$ \\
\hline$(\quad)$ & (parênteses vazios) & $\begin{array}{l}\text { segmento de fala que não pôde ser } \\
\text { transcrito }\end{array}$ \\
\hline $\begin{array}{c}\text { (palavra } \\
\text { ) }\end{array}$ & $\begin{array}{l}\text { (segmento de fala entre } \\
\text { parênteses) }\end{array}$ & $\begin{array}{l}\text { fala transcrita, mas com dúvida do } \\
\text { transcritor }\end{array}$ \\
\hline$\left[\begin{array}{ll}1 & ]\end{array}\right.$ & (colchetes) & $\begin{array}{l}\text { fala sobreposta (mais de um interlocutor } \\
\text { falando ao mesmo tempo) }\end{array}$ \\
\hline$=$ & (sinal de igual) & elocuções contíguas \\
\hline palavra & $\begin{array}{l}\text { (citação em itálico da fala no } \\
\text { texto) }\end{array}$ & $\begin{array}{l}\text { citações de elocuções dos excertos no } \\
\text { corpo do texto }\end{array}$ \\
\hline Maria & (pseudônimo) & $\begin{array}{l}\text { nome fictício para a identificação do } \\
\text { participante da interação }\end{array}$ \\
\hline q & (símbolo de feminino) & menina não identificada \\
\hline $0^{\pi}$ & (símbolo de masculino) & menino não identificado \\
\hline $\begin{array}{l}\text { ((olhand } \\
\text { o para } \\
\text { teto)) }\end{array}$ & $\begin{array}{l}\text { (parênteses duplos com } \\
\text { texto) }\end{array}$ & $\begin{array}{l}\text { descrição de atividade não verbal ou outra } \\
\text { observação do transcritor }\end{array}$ \\
\hline
\end{tabular}

